OPEN ACCESS

Edited by:

Yanbo Zhang,

University of Saskatchewan, Canada

Reviewed by:

Andrea Schmitt,

Ludwig Maximilian University of

Munich, Germany

Hans-Gert Bernstein,

Univ. Magdeburg, Germany

*Correspondence:

Natalya A. Uranova

uranovan@mail.ru

Specialty section: This article was submitted to Psychopathology,

a section of the journal

Frontiers in Psychiatry

Received: 10 December 2019 Accepted: 02 March 2020

Published: 26 March 2020

Citation:

Uranova NA, Vikhreva OV, Rakhmanova VI and Orlovskaya DD (2020) Dystrophy of Oligodendrocytes and Adjacent Microglia in Prefrontal Gray Matter in Schizophrenia.

Front. Psychiatry 11:204. doi: 10.3389/fpsyt.2020.00204

\section{Dystrophy of Oligodendrocytes and Adjacent Microglia in Prefrontal Gray Matter in Schizophrenia}

\author{
Natalya A. Uranova*, Olga V. Vikhreva, Valentina I. Rakhmanova and Diana D. Orlovskaya \\ Laboratory of Clinical Neuropathology, Mental Health Research Center, Moscow, Russia
}

Background: Some evidence support the notion that microglia activation in acute state of schizophrenia might contribute to damage of oligodendrocytes and myelinated fibers. Previously we found dystrophic changes of oligodendrocytes in prefrontal white matter in schizophrenia subjects displaying predominantly positive symptoms as compared to controls. The aim of the study was to verify whether microglial activation might contribute to dystrophic changes of oligodendrocytes in prefrontal gray matter in this clinical subgroup.

Methods: Transmission electron microscopy and morphometry of microglia and adjacent oligodendrocytes were performed in layer 5 of the prefrontal cortex (BA10) in the schizophrenia subjects displaying predominantly positive symptoms (SPPS, $n=12$ ), predominantly negative symptoms (SPNS, $n=9)$ and healthy controls $(n=20)$.

Results: Qualitative study showed microglial activation and dystrophic alterations of microglia and oligodendrocytes adjacent to each other in both subgroups as compared to controls. A significant reduction in volume density $(\mathrm{V} v)$ and the number $(\mathrm{N})$ of mitochondria and an increase in $\mathrm{N}$ of lipofuscin granules were found in oligodendrocytes and adjacent microglia in both subgroups. $V_{V}$ of lipofuscin granules, $V v$ and $N$ of vacuoles of endoplasmic reticulum in microglia were increased significantly in the SPPS subgroup as compared to controls. In the SPPS subgroup $\mathrm{V} v$ and $\mathrm{N}$ of mitochondria in microglia were correlated with $\mathrm{N}$ of vacuoles in microglia $(r=-0.61, p<0.05)$ and with $\mathrm{Vv}(r=0.79$, $p<0.01)$ and $N(r=0.59, p<0.05)$ of mitochondria in oligodendrocytes. $V_{v}$ of mitochondria in microglia was also correlated with $V_{v}$ and $N$ of vacuoles in oligodendrocytes in the SPPS subgroup $(r=0.76, p<0.01)$. Area of nucleus of microglial cells was correlated negatively with age $(r=-0.76, p<0.01)$ and age at illness onset $(r=-0.65, p<0.05)$ in the SPPS subgroup. In the SPNS subgroup $N$ of mitochondria in microglia was correlated with $\mathrm{V} v$ of lipofuscin granules in oligodendrocytes $(r=-0.9, p<0.01)$. There were no significant correlations between these parameters in the control group.

Discussion: Microglial dystrophy might contribute to oligodendrocyte dystrophy in the schizophrenia subjects with predominantly positive symptoms during relapse. Mitochondria in microglia and oligodendrocytes may be a target for treatment strategy of schizophrenia.

Keywords: prefrontal cortex, postmortem, oligodendrocytes, microglia, ultrastructure, morphometry, schizophrenia 


\section{INTRODUCTION}

Neuroimaging studies provide increasing evidence for functional dysconnectivity and the alteration of white matter integrity in schizophrenia $(1,2)$. The prefrontal cortex (PFC) is one of the main brain structure affected in schizophrenia (3). Functional dysconnectivity of the PFC is known to be associated with psychotic symptoms and cognitive dysfunctions in schizophrenia (4). Severity of positive symptoms is linked with microstructural abnormalities in the PFC (5) and functional dysconnectivity in fronto-temporal cortex in patients with schizophrenia (6). Garver et al. (7) in DTI study showed that an increase in $\mathrm{Dm}$ in drug-free schizophrenia patients was reduced following the reduction of psychotic symptoms after antipsychotic drug treatment.

Pathology of oligodendrocytes and myelin is considered to be a biological basis for dysconnectivity in schizophrenia $(2,8)$. Reduced oligodendrocyte density (9-12), ultrastructural alterations of oligodendrocytes and myelinated fibers (13-15), altered intracortical myelin staining (16) and impaired differentiation of oligodendrocyte precursors (17) have been reported in the PFC in schizophrenia. Abnormalities of myelination, reduced expression and dysregulation of oligodendrocyte and myelin-related genes (18-20) have been detected in the PFC in schizophrenia.

The mechanisms of oligodendrocyte and myelin abnormalities in schizophrenia remain uncertain. Oligodendrocytes are often located adjacent to microglial cells in both control and schizophrenia (21). Previously we found dystrophic alterations in oligodendrocytes adjacent to microglia and myelin in the prefrontal white matter in the schizophrenia patients with predominantly positive symptoms as compared to controls (21). These data suggest the involvement of microglial activation in oligodendrocyte abnormalities in schizophrenia. Microglia hypothesis of schizophrenia supposes that microglial overactivation is crucial in the etiology of schizophrenia (22). Multiple lines of evidence for a role of neuroinflammation and oxidative stress in the pathophysiology of psychosis (23) and increased expression of genes associated to immune and chaperone functions in the PFC (24) have been reported in schizophrenia. Microglial activation in brain of the schizophrenia patients has been reported both in vivo (25) and postmortem $(26,27)$ studies. Some postmortem studies detected an increased microglial density in a subpopulation of schizophrenia patients (28-32). Steiner et al. (32) showed a significantly increased density of activated microglia in patients with schizophrenia who committed suicide during acute psychosis as compared to nonsuicidal patients with schizophrenia in the dorsolateral PFC. Busse et al. (33) found a significant difference in microglial density between patients with paranoid and residual schizophrenia. Fillman et al. (31) have reported increased inflammatory mRNA expression in $\sim 40 \%$ of schizophrenia patients. These data indicate increased microglial density in a subpopulation of patients with schizophrenia.

Neuroimaging studies of psychotic patients support a link between microglial activation and psychosis (34), sub-clinical psychotic symptoms (35), severity of psychotic symptoms (36), age- dependent pattern of microglial activation in male psychosis patients (37), illness duration (38). Fillman et al. (39) have recently reported that schizophrenia patients with increased cytokine level showed significantly worse than patients with low-cytokine level on verbal fluency and reduced volume of pars opercularis (Broca's area). Dysregulated glutathione homeostasis was found in the PFC in early psychosis patients (40). Patients with early onset of schizophrenia showed greater and progressive loss of frontal gray matter in the first few years after disease onset. (41). These data suggest that neuroinflammation might be present in different subgroups of schizophrenia patients. Previously we found lowered oligodendrocyte density in layer 5 of the PFC in the schizophrenia patients (12). We hypothesized that oligodendrocyte dystrophy may be at least in part associated with increased activation of microglial cells located adjacent to dystrophic oligodendrocytes in the schizophrenia patients during acute psychosis. We aimed to estimate ultrastructural parameters of microglia and oligodendrocytes adjacent to each other in layer 5 of the PFC in two subgroups of patients with schizophrenia - those displaying predominantly positive symptoms and those displaying predominantly negative symptoms.

\section{MATERIAL AND METHODS}

\section{Subjects}

21 cases with schizophrenia and 20 normal controls were studied. Postmortem brain tissue was obtained from the Anatomical Department of Moscow Psychiatric Hospitals №1 and № 15 and Moscow Higher Medical School. ICD-10 and DSM-IV-R diagnostic criteria were used by psychiatrists. Independent psychiatrists examined medical records using the Scale for the Assessment of Negative Symptoms (SANS) and the Scale for the Assessment of Positive Symptoms (SAPS) to rate negative and positive symptoms during the last hospitalization in the schizophrenia patients. The predominantly positive or the predominantly negative symptoms were estimated based on some integrative characteristics including common score of positive and negative symptoms (in points), relative frequency (\%) of positive and negative symptoms, and relative frequency (\%) of the most severe positive and negative symptoms. Basic demographic and clinical data are given in Table 1. Consent for autopsy was obtained and approval for the study from the Ethics Committee of Mental Health Research Center was received. Exclusion criteria were alcohol, drug abuse, other neuropsychiatric disorders. Cases were excluded from the study by an experienced neuropathologist if there was evidence for neurological damage, neoplasmic, vascular and neurodegenerative changes. Cases were coded and morphometric study was performed blindly. Samples of the frontal lobe (Brodmann's area 10) from the left hemisphere were dissected from the brains. Data on age at onset, duration of illness and neuroleptic exposure were obtained from medical records. Also chlorpromazine equivalents were estimated for the patient's last 30 days. Causes of death were the same in the control and the schizophrenia groups [see (21)].

\section{Tissue Preparation}

Tissue preparation was described in details in our previous paper (21). Sections were viewed with a JEM-100B (JEOL, Japan) 
TABLE 1 | Demographic and clinical data (mean \pm standard deviation).

\begin{tabular}{|c|c|c|c|c|c|c|}
\hline Subjects & Number per group & Gender $^{a}$ & $\begin{array}{l}\text { Age }(\text { years) } \\
\text { Mean } \pm \text { SD }\end{array}$ & $\begin{array}{l}\text { PMI (hours) } \\
\text { Mean } \pm \text { SD }\end{array}$ & $\begin{array}{l}\text { Duration of illness (years) } \\
\text { Mean } \pm S D\end{array}$ & $\begin{array}{c}\text { NTR (chlorpromazine equivalents) } \\
\text { Mean } \pm \text { SD }\end{array}$ \\
\hline Controls & 20 & $12 \mathrm{M}, 8 \mathrm{~F}$ & $58.3 \pm 12.6$ & $6.1 \pm 1.0$ & & \\
\hline Schizophrenia & 21 & $11 \mathrm{M}, 10 \mathrm{~F}$ & $56.3 \pm 16.8$ & $6.2 \pm 1.0$ & $28.2 \pm 13.0$ & $406.5 \pm 303.6$ \\
\hline SPNS & 9 & $5 \mathrm{M}, 4 \mathrm{~F}$ & $56.2 \pm 17.8$ & $5.6 \pm 0.7$ & $29.3 \pm 15.7$ & $457.0 \pm 378.6$ \\
\hline SPPS & 12 & $6 \mathrm{M}, 6 \mathrm{~F}$ & $56.4 \pm 16.8$ & $6.6 \pm 1.1$ & $27.42 \pm 13.0$ & $367.2 \pm 253.1$ \\
\hline
\end{tabular}

PMI, postmortem interval. SPPS, the subgroup with predominantly positive symptoms; SPNS, the subgroup with predominantly negative symptoms; NTR, neuroleptic treatment. Controls vs. SCZ: ${ }^{a}$ Chi-square test $(p=0.43),{ }^{b}$ ANOVA $(p=0.92),{ }^{c}$ ANOVA $(p=0.24)$.

electron microscope. Electron micrographs of oligodendrocytes were obtained at ${ }^{\star} 3300$ magnification. Oligodendrocytes were identified by small round or oval nucleus, short cisternae of granular endoplasmic reticulum, polyribosomes and the Golgi complex. Microglial cell bodies had elongated, round or triangular nuclei with electron- dense heterochromatin. Cytoplasm of these cells contains mitochondria, cisternae of endoplasmic reticulum, lysosomes, lipofuscin granules, Golgi complex.

\section{Morphometry}

Morphometry was performed for microglia adjacent to oligodendrocytes and oligodendrocytes adjacent to microglia. Mean number of microglia/oligodendrocyte pairs per case \pm S.D. collected were: $11.8 \pm 3.5$ for the control group and $13.05 \pm 3.6$ for the schizophrenia group. These cells were measured within the area (mean \pm S.D.) $0.21 \pm 0.06 \mathrm{~mm}^{2}$ in the control group and $0.19 \pm 0.05 \mathrm{~mm}^{2}$ in the schizophrenia group. Cell density was estimated as the number of cells per unit tissue area $\left(\mathrm{N} / \mathrm{mm}^{2}\right)$. Cell size, nucleus/cytoplasm ratio, volume fraction $(\mathrm{Vv})$ and the number $(\mathrm{N})$ of organelles (mitochondria, vacuoles of endoplasmic reticulum, lipofuscin granules) were measured. Areas of cells and cellular organelles were estimated using test grids for two-dimensional counts, superimposed on the negatives at the final magnification ${ }^{\star} 26,000$. The counting method was previously described in details (21).

\section{Statistical Analysis}

Statistica software, version 7 (Stat Soft) was used for statistical analysis. The data were examined using the KolmogorovSmirnov test for normality. A Pearson correlation analysis was performed to detect possible correlations between the parameters measured and age, postmortem interval, treatment with antipsychotic drugs (CPZ equivalents), illness duration. The groups did not differ significantly by age $(\mathrm{p}=0.9)$ and postmortem delay $(\mathrm{p}=0.2)$. ANCOVA comparisons between the schizophrenia patients and controls were performed with cell parameters measured as dependent variables, diagnosis as independent factor, and age and post-mortem interval as covariates. To determine the effect of clinical subgroups on the parameters measured, ANCOVA was used with cell parameters as dependent variables, clinical SPPS and SPNS subgroups as between-subjects factors, and age and postmortem interval as covariates. To determine the effect of gender, duration of disease ( $<26$ years and $>26$ years, group median), age at onset of disease on the parameters measured ANCOVA was used with the cell parameters as dependent variables, diagnosis and gender or disease duration or age at onset of disease as between-subjects factors, and age and postmortem interval as covariates. Following ANCOVA, we performed a post-hoc Duncan test. Cohen's $\mathrm{d}$ in the Statistica software was used to determine effect size.

\section{RESULTS}

Table 1 contains demographic and clinical data. The ultrastructure of microglia was heterogeneous in the control group and in both clinical subgroups of schizophrenia subjects. Four different ultrastructural types of microglia were found: "resting", ameboid (activated), dystrophic and apoptotic. "Resting" microglia contained relatively small cytoplasm, few mitochondria and cisterns of endoplasmic reticulum (Figure 1A). Ameboid (activated) microglial cells was detected by cytoplasmic hypertrophy, many normal mitochondria and vacuoles of enlarged cisterns of endoplasmic reticulum. (Figure 1B). Dystrophic microglia contained few swollen mitochondria with destroyed cristae, numerous vacuoles of enlarged cisterns of endoplasmic reticulum of different size and lipofuscin granules (Figures 1C, D). The nucleus of many dystrophic microglial cells was dark due to electron-dense cytoplasm and nucleoplasm (Figure 2A). Some of these cells showed signs of apoptosis (dark nucleus and small rim of dark shrunken cytoplasm (Figures 2B-D). Activated (Figure 1B), dystrophic and apoptotic microglia (Figures 2A-D) were often rodshaped and touched the nucleus of oligodendrocytes suggesting direct contacts. Intermediate subtypes of microglia were also observed in both subgroups studied and in the control group. Oligodendrocytes adjacent to microglia in schizophrenia cases looked swollen, vacuolated as compared to controls, contained small amount of ribosomes and lipofuscin granules (Figure 1C). Some oligodendrocytes mostly in the schizophrenia subjects contained abnormal large vacuoles, a sign of focal lysis of their cytoplasm (Figures 1B, C).

We found the effect of diagnosis on the parameters of microglia adjacent to oligodendrocytes (Table 2). Schizophrenia group showed a significant decrease in area, $\mathrm{Vv}$ and $\mathrm{N}$ of mitochondria $(\mathrm{p}<0.001)$ and a significant increase in area, $\mathrm{N}$ $(\mathrm{p}<0.05)$ and $\mathrm{Vv}$ of vacuoles $(\mathrm{p}<0.01)$ as well as an increase in area, $\mathrm{N}(\mathrm{p}<0.01)$ and $\mathrm{Vv}(\mathrm{p}<0.001)$ of lipofuscin granules as compared to the control group. A significant effect of diagnosis was also found on $\mathrm{Vv}$ and $\mathrm{N}$ of mitochondria, vacuoles, and lipofuscin granules in oligodendrocytes (Table 2). Area, Vv and N of mitochondria $(\mathrm{p}<0.001)$ were lower but area $(\mathrm{p}<0.01)$ and $\mathrm{N}$ 

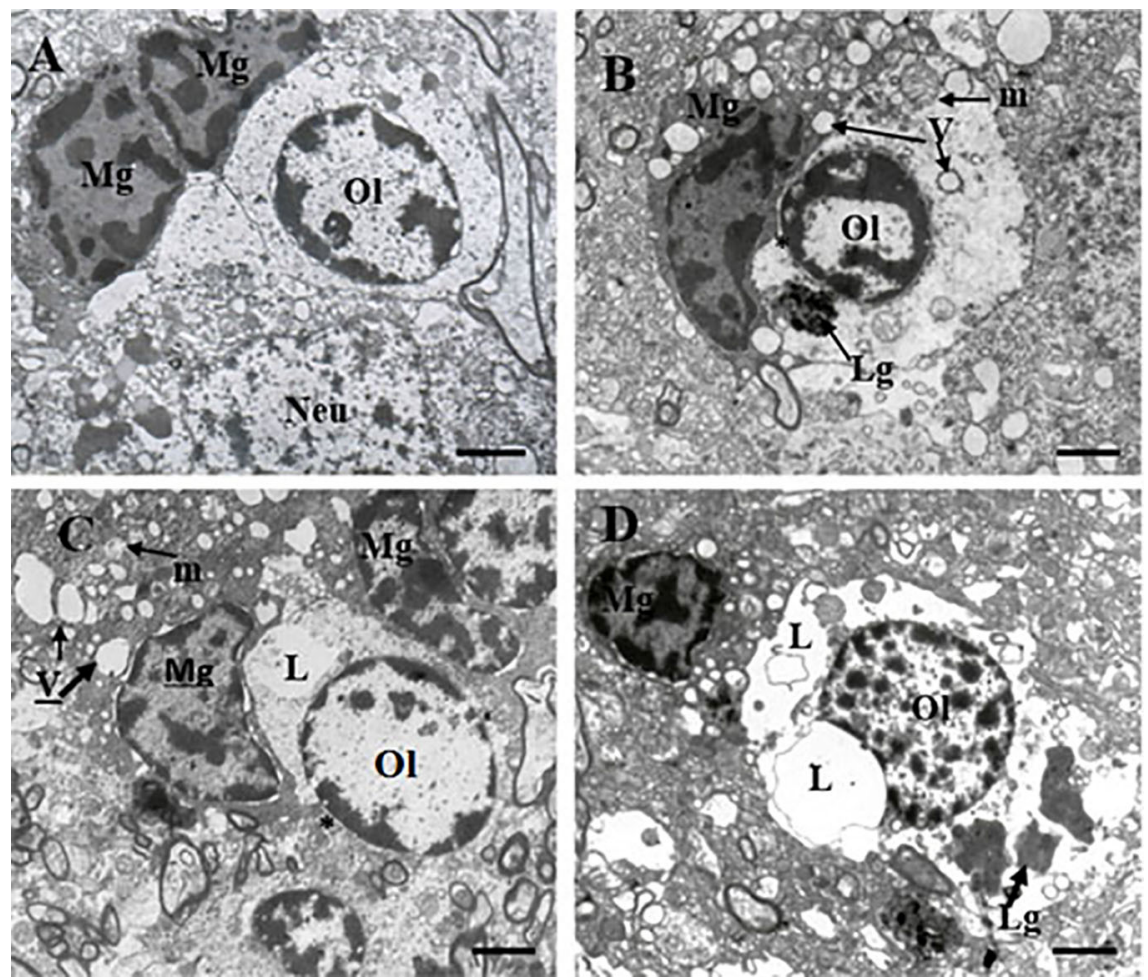

FIGURE 1 | These micrographs from layer 5 of the prefrontal cortex show microglia adjacent to oligodendrocytes from control brain (A) and from the SPPS subgroup (B-D). "Resting" microglia (A). Ameboid (activated) microglia (B). Dystrophic changes in microglia and oligodendrocytes: cytoplasm vacuolation, damaged mitochondria, accumulation of lipofuscin granules (C, D). Microglial cytoplasm contacts with oligodendrocyte nucleus (B, C, *). Focal lysis (L) of cytoplasm of oligodendrocytes adjacent to microglia (C, D). Mg, microglia; Ol, oligodendrocyte, m, mitochondria (arrows); V, vacuole (arrows), Lg, lipofuscin granule (arrows). (Scale bars $=1 \mu \mathrm{m})$

$(\mathrm{p}<0.05)$ of vacuoles, area, $\mathrm{Vv}$ and $\mathrm{N}$ of lipofuscin granules $(\mathrm{p}<$ $0.001)$, area of oligodendrocyte cell and cytoplasm $(\mathrm{p}<0.01)$ were higher in the schizophrenia group as compared to the control group. Effect size for these parameters of microglia and adjacent oligodendrocytes was large (Table 2). Cell density was not changed (Table 2).

We also found a significant effect of clinical subgroups on the same ultrastructural parameters of microglia and oligodendrocytes adjacent to each other (Table 2). Post-hoc showed a significantly lowered $\mathrm{Vv}$ and $\mathrm{N}$ of mitochondria in the SPPS subgroup $(\mathrm{p}<0.01)$ and in the SPNS subgroup $(\mathrm{p}<0.001)$ in both microglia (Figures $\mathbf{3 A}, \mathbf{B}$ ) and in oligodendrocytes (Figures 3G, H) as compared to controls. $\mathrm{Vv}$ of lipofuscin granules in microglia was increased only in the SPPS subgroup ( $\mathrm{p}<0.01$ ), but $\mathrm{N}$ of lipofuscin granules in microglia, $\mathrm{Vv}$ and $\mathrm{N}$ of lipofuscin granules in oligodendrocytes were higher in both clinical subgroups as compared to controls (Figures $\mathbf{3 B}, \mathbf{I}, \mathbf{J})$. $\mathrm{Vv}$ and $\mathrm{N}$ of vacuoles in microglia were higher only in the SPPS subgroup ( $p<0.01, p<0.05$ ) compared to controls (Figures 3C-F). However, in oligodendrocytes $\mathrm{Vv}$ of vacuoles was not changed significantly, and $\mathrm{N}$ of vacuoles were higher in both clinical subgroups $(\mathrm{p}<0.01)$ (Figures $3 \mathbf{K}, \mathbf{L})$.

Correlations analysis demonstrated that only in the SPPS subgroup $\mathrm{Vv}$ and $\mathrm{N}$ of mitochondria in microglia were correlated positively with $\mathrm{Vv}(\mathrm{r}=0.79, \mathrm{p}<0.01)$ and $\mathrm{N}(\mathrm{r}=0.58, \mathrm{p}<0.05)$ of mitochondria in oligodendrocytes (Figures $4 \mathbf{A}, \mathbf{B}$ ). In this subgroup $\mathrm{Vv}$ of mitochondria in microglia was correlated positively with $\mathrm{Vv}(\mathrm{r}=0.77, \mathrm{p}<0.01)$ and $\mathrm{N}(=0.76, \mathrm{p}<0.01)$ of vacuoles in oligodendrocytes (Figures $4 C, D$ ). Besides, in the SPPS subgroup $\mathrm{Vv}$ and $\mathrm{N}$ of mitochondria was correlated negatively with $\mathrm{N}$ of vacuoles in microglia $(\mathrm{r}=-0,61, \mathrm{p}<0.05)$ (Figures 4E, F). Vv of mitochondria in oligodendrocytes was positively correlated with $\mathrm{N}$ of vacuoles in oligodendrocytes in the SPPS subgroup $(\mathrm{r}=0.78, \mathrm{p}<0.01)$ as well as in the control group $(\mathrm{r}=0.47, \mathrm{p}<0.05)$ (Figure 5A). In the SPPS subgroup area of nucleus of microglia was correlated negatively with age $(\mathrm{r}=$ $-0.76, \mathrm{p}<0.01)$ and age at onset of disease $(\mathrm{r}=-0.65, \mathrm{p}<0.05)$ (Figures 5C, D). In the SPNS subgroup $\mathrm{N}$ of mitochondria in microglia was correlated with $\mathrm{Vv}$ of lipofuscin granules in oligodendrocytes $(\mathrm{r}=-0.9, \mathrm{p}<0.01)$ (Figure 5B).

Comparison of the parameters measured in oligodendrocytes and microglia in the SPPS and the SPNS subgroups with shorter $(<26$ years) and longer ( $>26$ years) duration of disease showed that in the SPPS subgroup Vv and $\mathrm{N}$ of mitochondria in both microglia and oligodendrocytes was significantly lower in the subgroup with longer duration of disease than in the subgroup with shorter duration of disease $(p<0.05)$ (Figures 6A-D). Vv 

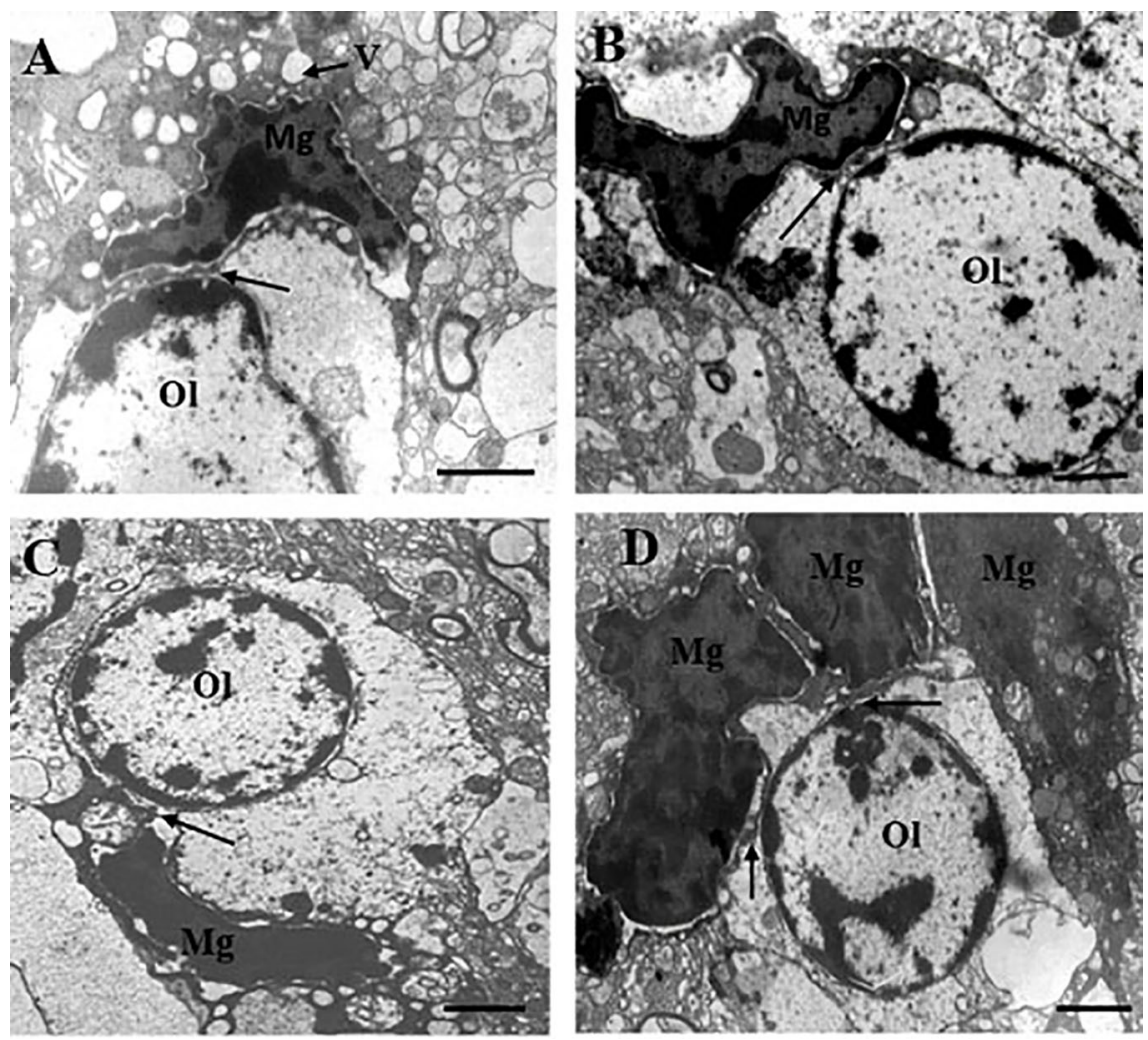

FIGURE 2 | These micrographs from layer 5 of the prefrontal cortex show microglia adjacent to oligodendrocytes from the SPNS subgroup. Dark dystrophic microglia (A). Ameboid microglia (B), signs of apoptosis (dark nucleus and small rim of dark shrunken cytoplasm) (C, D). All microglia showed contacts with the nuclei of oligodendrocytes (A-D, arrows). A group (cluster) of three microglia surrounding dystrophic oligodendrocyte (D). Ol, oligodendrocyte; Mg, microglia. Scale bar $=1 \mu \mathrm{m}$.

and $\mathrm{N}$ of vacuoles in microglia was significantly higher in the subgroup with longer duration of disease as compared to the control group ( $\mathrm{p}<0.05$ ) (Figures 6E, F).

Only in the SPPS subgroup $\mathrm{VV}$ and $\mathrm{N}$ of mitochondria in microglia were positively correlated with microglial density $(\mathrm{r}=$ $0.78, \mathrm{r}=0.77, \mathrm{p}<0.01)$. Alternatively, $\mathrm{Vv}$ and $\mathrm{N}$ of vacuoles in microglia were correlated negatively with microglial density $(\mathrm{r}=$ $-0.72, \mathrm{p}<0.01 ; \mathrm{r}=-0.69, \mathrm{p}<0.05$ ) (Figures 7C, D). ANCOVA showed no significant effects of age, postmortem interval or gender on the parameters measured. No significant correlations between the parameters measured and postmortem interval, neuroleptic treatment were found.

\section{DISCUSSION}

The present study showed dystrophic alterations in microglia adjacent to oligodendrocytes and in oligodendrocytes adjacent to microglia in the schizophrenia group and in the SPPS and SPNS subgroups. The mean values of $\mathrm{Vv}$ and the $\mathrm{N}$ of mitochondria were significantly decreased while $\mathrm{N}$ of lipofuscin granules in microglia and oligodendrocytes were increased in the schizophrenia group as compared to the control group. However
$\mathrm{Vv}$ of lipofuscin granules, $\mathrm{Vv}$ and $\mathrm{N}$ of vacuoles of endoplasmic reticulum in microglia were increased significantly only in the SPPS subgroup as compared to controls. These data provide evidence for more prominent alterations of microglia in the SPPS subgroup than in the SPNS subgroup. The important finding was the presence of positive correlations between $\mathrm{Vv}$ and $\mathrm{N}$ of mitochondria in microglia and $\mathrm{Vv}$ and $\mathrm{N}$ of mitochondria in oligodendrocytes as well as between $\mathrm{Vv}$ of mitochondria in microglia and $\mathrm{Vv}$ and $\mathrm{N}$ of vacuoles in oligodendrocytes only in the SPPS subgroup. These data point that dystrophic alterations in microglia are associated with the dystrophic alterations in oligodendrocytes in the SPPS subgroup. In the SPNS subgroup $\mathrm{N}$ of mitochondria in microglia correlated negatively with $\mathrm{Vv}$ of lipofuscin granules in oligodendrocytes. There were no significant correlations between all these parameters in the control group. Also, there were no significant effects of postmortem interval or gender, as well as no significant correlations between the parameters measured and postmortem interval, neuroleptic treatment. Neurodegenerative changes were excluded in the cases studied in neuropathological examination. Taken together, these data suggest that altered relationships between microglia and oligodendrocytes are associated with chronic schizophrenia and with deleterious effect of the disturbed metabolism in microglia on the oligodendrocyte metabolism in the SPPS subgroup in acute 
TABLE 2 | Effect of diagnosis on microglia adjacent to oligodendrocytes and on oligodendrocytes adjacent to microglia.

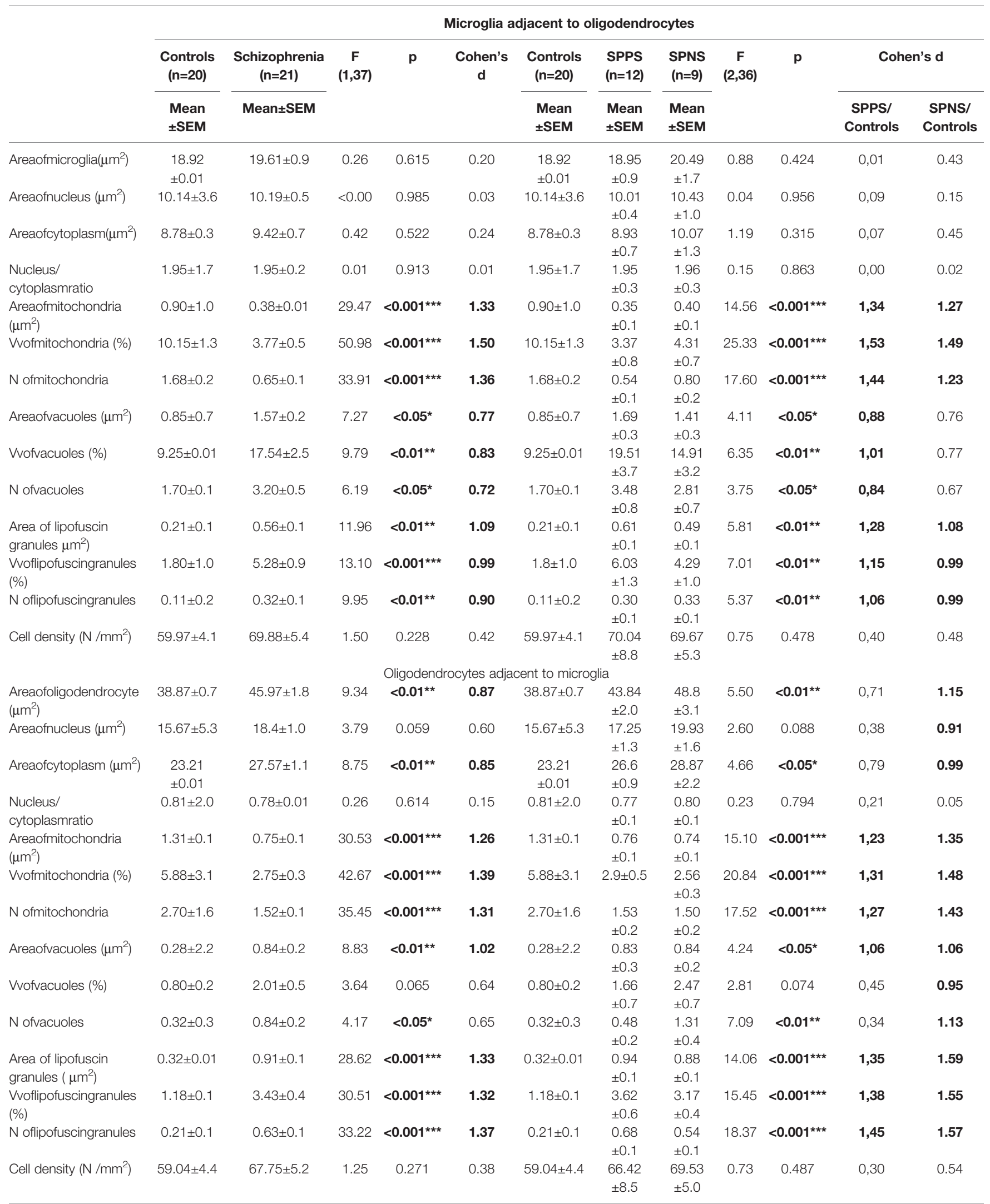

${ }^{*} p<0.05,{ }^{* *} p<0.01,{ }^{* * *} p<0.001$. 

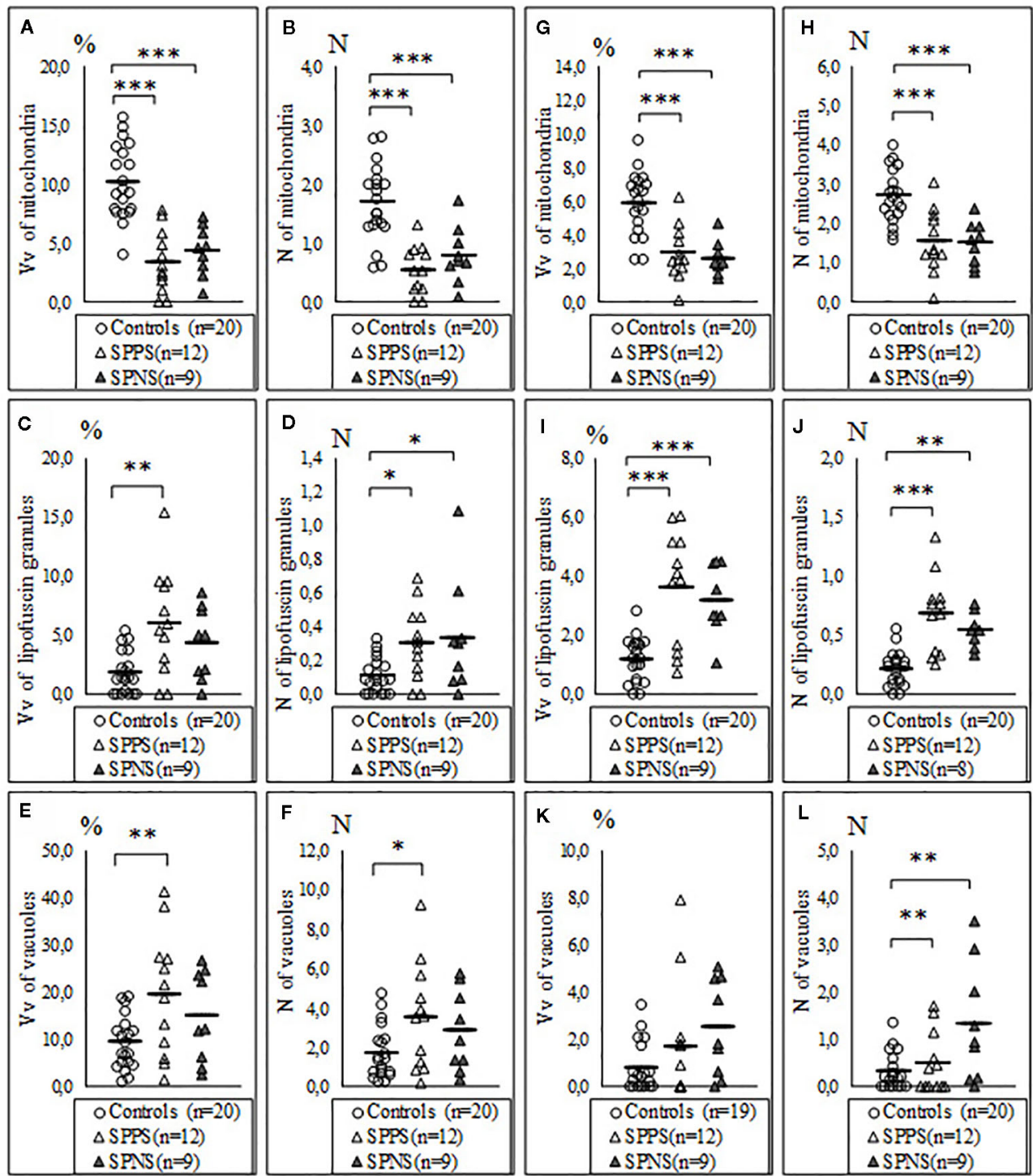

FIGURE 3 | Individual and mean values for VV and $\mathrm{N}$ of mitochondria (A, B), lipofuscin granules (C, D), vacuoles (E, F) in microglia adjacent to oligodendrocytes, in oligodendrocytes adjacent to microglia (G-L) for the control group, the subgroup with predominantly positive symptoms (SPPS) and the subgroup with predominantly negative symptoms (SPNS). ${ }^{*} \mathrm{p}<0.05,{ }^{\star \star} \mathrm{p}<0.01,{ }^{\star \star *} \mathrm{p}<0.001$.

stage of disease, during relapse. Similar alterations of oligodendrocytes adjacent to microglia have been previously reported in the prefrontal white matter in chronic schizophrenia cases (21).

We found significant positive correlations between $\mathrm{Vv}$ and $\mathrm{N}$ of mitochondria in microglia and $\mathrm{Vv}$ and $\mathrm{N}$ of mitochondria in oligodendrocytes only in the SPPS subgroup. These data as well as the deficit of mitochondria in both microglia and in oligodendrocytes suggest that the damage and deficit of mitochondria in microglia and in oligodendrocytes may be crucial in the disturbance of microglial and oligodendrocyte metabolism in schizophrenia, especially in the SPPS subgroup, during acute state of disease. Mitochondria play a key role in cellular energy potential, calcium buffering, production of reactive oxygen species (ROS), they participate in regulation of apoptosis $(42,43)$. The deficits of mitochondria found in the present study is consistent with alterations in mitochondrial ultrastructure and number $(13-15,44)$, energy metabolism and oxidative stress, including the PFC (45-47). Defect of oxidative phosphorylation (reduced activity of complex IV) in the frontal cortex (48), altered expression of mitochondria-related genes including encoding respiratory chain components (49) have been reported in schizophrenia.

Flatow et al. (50) provide evidence for oxidative stress as a "potential biomarker in the pathophysiology and clinical course of schizophrenia". Mitochondrial dysregulation may lead to 

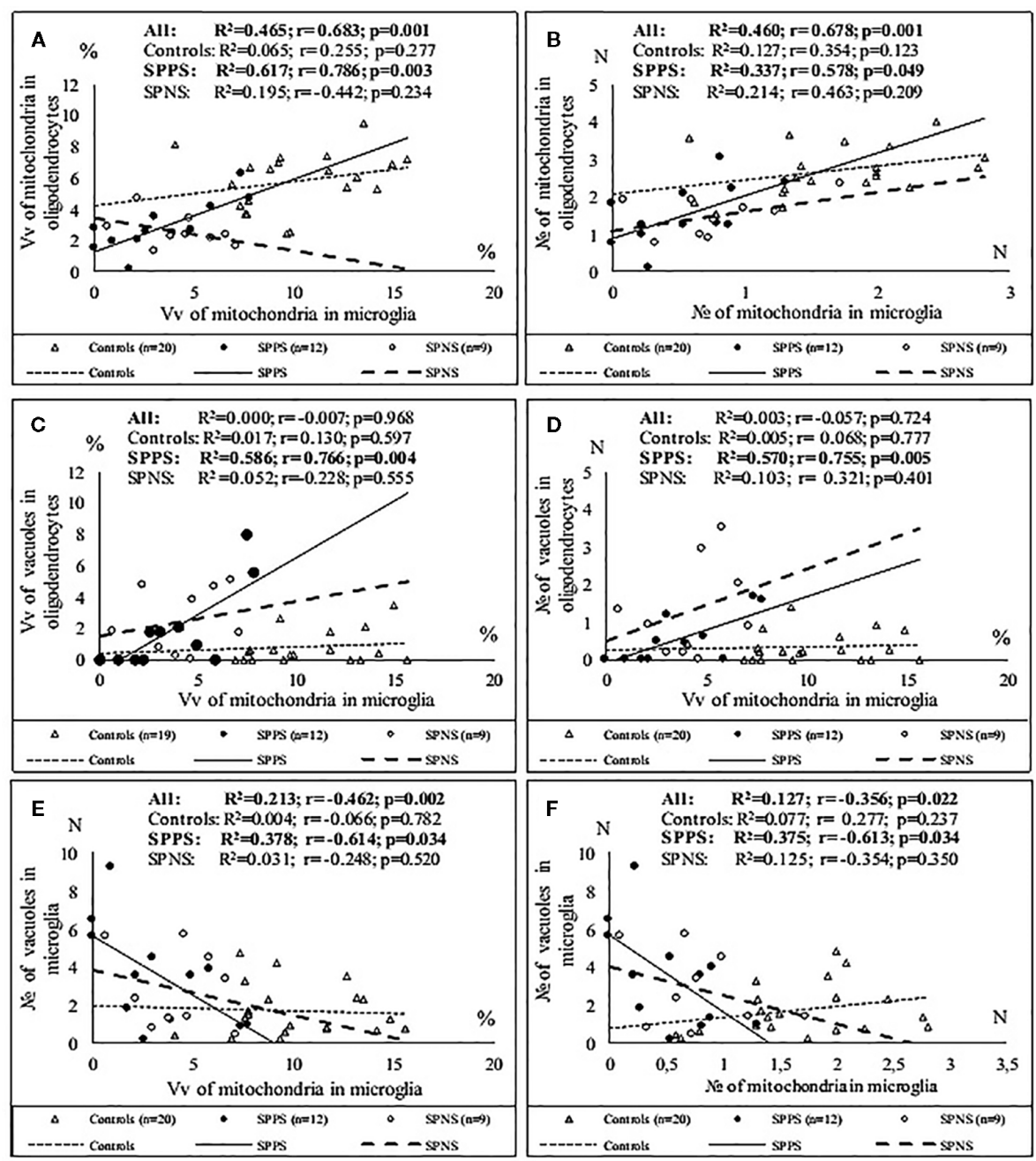

FIGURE 4 | Positive significant correlations between $\mathrm{V} v$ and $\mathrm{N}$ of mitochondria in microglia and $\mathrm{V} v$ and $\mathrm{N}$ of mitochondria in oligodendrocytes (A, B); positive significant correlations between $\mathrm{V} v$ of mitochondria in microglia and $\mathrm{V} v$ and $\mathrm{N}$ of vacuoles in oligodendrocytes (C, D) and negative significant correlations between $\mathrm{V} V$ and $\mathrm{N}$ of mitochondria and $\mathrm{N}$ of vacuoles in microglia (E, F) in the SPPS subgroup.

oxidative stress and inflammation (51). Mitochondrial regulation of psychological stress reactivity systems has been recently reviewed (52). Postmortem studies have shown reduced levels of anti-oxidant glutathione in the PFC in chronic schizophrenia patients $(53,54)$. In response to oxidative stress damaged mitochondria might activate immuno-inflammatory pathways (55). ROS activation of transcription factors induced the expression of inflammatory genes (56). Also, postmortem studies demonstrated increased expression of immune-related genes in the PFC in schizophrenia (57). Thus, mitochondria abnormalities found in the present study are consistent with the alterations in mitochondrial energy metabolism, oxidative stress and neuroinflammation in schizophrenia, including the PFC. Mitochondria have contacts with endoplasmic reticulum (ER), and $\mathrm{Ca}^{2+}$ flux from the ER to mitochondria supports the Krebs cycle (43). Interestingly, some evidence suggests microglial intracellular $\mathrm{Ca}^{2+}$ signaling as a target of antipsychotic effects for the treatment of schizophrenia (58). Stressors disturb ER homeostasis, and the misfolded proteins may induce ER stress (43). In mammals, several viruses, invasive bacteria and parasites induce ER stress responses (59). ER stress and increases in ROS production activate autophagy to degrade stressed cellular organelles to restore homeostasis $(43,60)$. Mitochondrial autophagy, or mitophagy, has an important role in mitochondrial homeostasis, dysfunction and aging (61). Bernstein et al. (62) hypothesized that increased mitochondrial phagy (mitophagy) in oligodendrocytes might participate in white matter pathology in schizophrenia. Taken together, these data support a crucial role of damage and deficit of mitochondria in disturbed metabolism and in the dysfunction of microglia and adjacent oligodendrocytes in schizophrenia.

Our study indicated a significant increase in $\mathrm{Vv}$ and $\mathrm{N}$ of vacuoles only in the SPPS subgroup as compared to controls. Qualitative study showed that vacuoles are formed by enlarged 

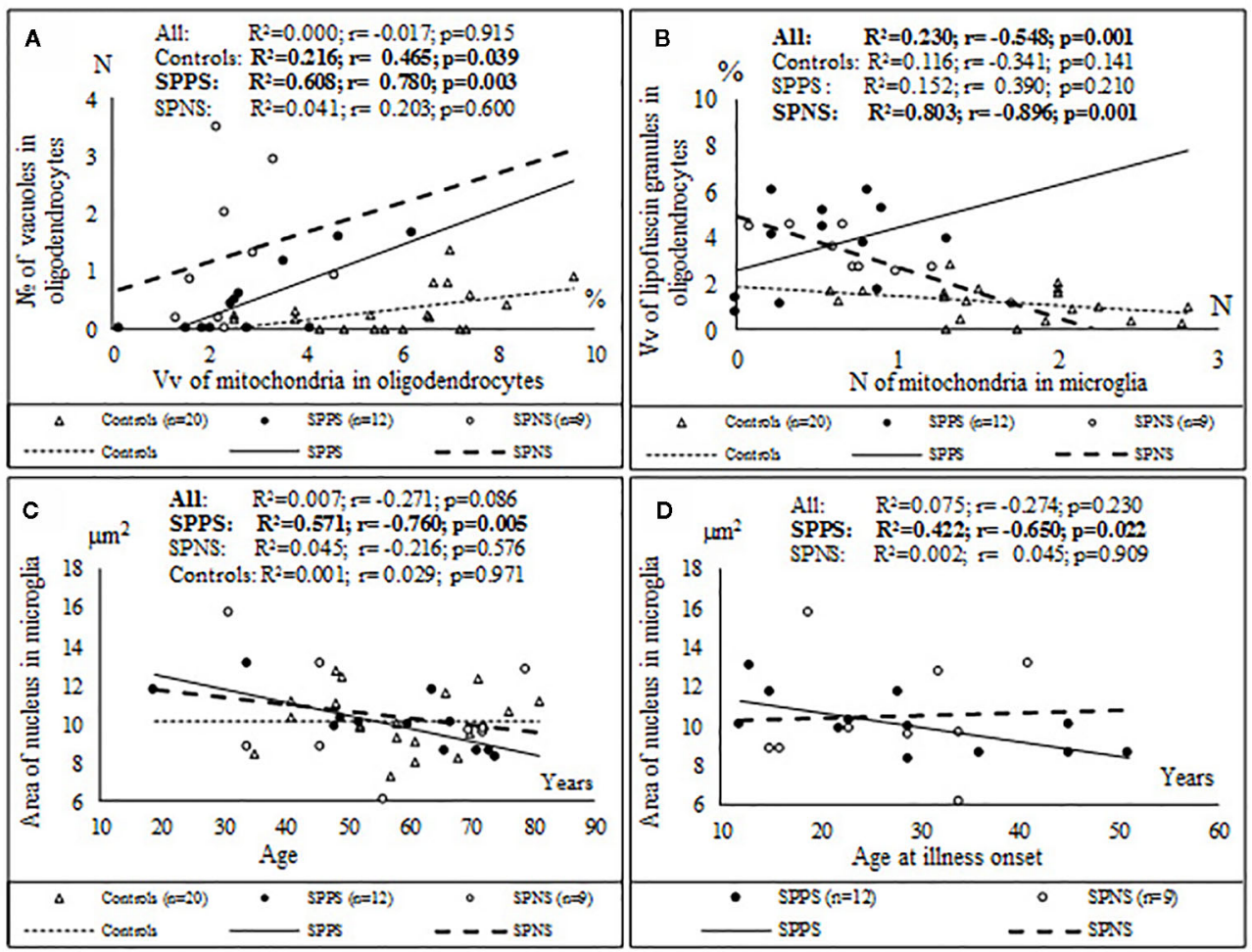

FIGURE 5 | Positive significant correlations between $\mathrm{V} v$ of mitochondria in oligodendrocytes and $\mathrm{N}$ of vacuoles in oligodendrocytes in the SPPS subgroup and in the control group (A); negative significant correlations between $\mathrm{N}$ of mitochondria in microglia and Vv of lipofuscin granules in oligodendrocytes in the SPNS subgroup (B) and negative significant correlations between area of nucleus of microglia and age (C) and age at onset of disease (D) in the SPPS subgroup.

cisterns of rough endoplasmic reticulum. Vv of vacuoles of ER and lipofuscin granules were significantly increased in microglia and in oligodendrocytes in the SPPS subgroup as compared to the control group. The ultrastructural marker of ER stress is a lumen dilation of rough ER $(63,64)$. Vacuoles in microglia present dilated cisterns of rough ER, and increased $\mathrm{Vv}$ and number of vacuoles found in our study only in the SPPS subgroup appear to reflect ER stress.

ER stress regulates differentiation, activation of immune cells and cytokine expression (65). ER stress can trigger inflammation associated with damaged mitochondria (66). An NLRP3caspase-2-dependent mechanism is necessary to connect ER stress to mitochondria to induce inflammation (66). In patients with schizophrenia inflammation and oxidative stress may influence each other resulting cellular damage (67). Taken together, these data suggest that altered communication between mitochondria and ER stress in microglia (in the SPPS subgroup) might contribute to increased production of proinflammatory cytokines in acute state of schizophrenia. The deficit of mitochondria, a significant increase in $\mathrm{Vv}$ and $\mathrm{N}$ of vacuoles in microglia and negative correlations of $\mathrm{N}$ of vacuoles with $\mathrm{Vv}$ and $\mathrm{N}$ of mitochondria found in microglia in the SPPS subgroup suggest that microglia in the SPPS subgroup may be compensatory overactivated due to ER stress, because increased number of vacuoles coexists with the deficit of mitochondria.
Our study showed different signs of microglial activation in schizophrenia: the presence of activated microglia (Figure 1B), contacts between microglial cytoplasm and nucleus of oligodendrocytes in schizophrenia but rare in the controls; irregular contour of nuclei and numerous vacuoles in cytoplasm of many microglial cells; focal lysis of cytoplasm of oligodendrocytes located near the contact with microglia supposedly due to toxic microglia effect on oligodendrocytes.

The presence of continuum of microglial cells from activated to prominent dystrophy and apoptosis of microglia found in the present study suggest that prolonged activation of microglial cells in the course of the disease might make these cells exhaustive and degenerating in chronic schizophrenia patients and might decrease their protective potential for oligodendrocytes and for other cells as well as the plasticity of microglia and oligodendrocytes in schizophrenia. Degeneration of microglia has been found in the frontal and temporal cortex in schizophrenia (68). In our study the cytoplasm of both dystrophic dark and apoptotic microglia touched the nucleus of oligodendrocytes suggesting direct contacts, a sign of their activation. Similar "dark" microglia becomes numerous during chronic stress (64). Dark microglia is supposed to be much more active than the normal microglia (64). Thus, our data indicate that microglia from patients with schizophrenia is in broad spectrum of changes - from activated to degenerating. 

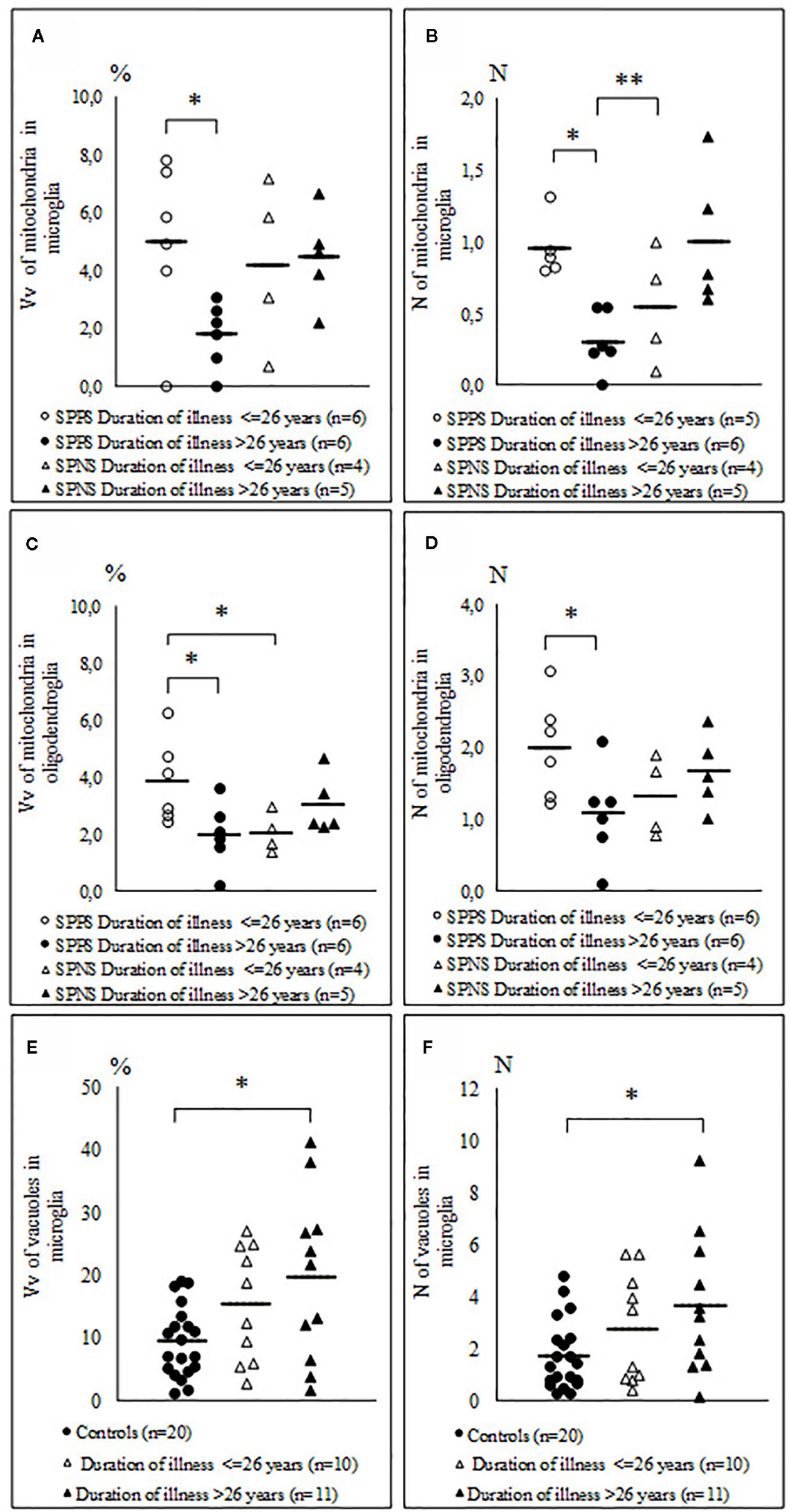

FIGURE 6 | Individual and mean values for Vv and $\mathrm{N}$ of mitochondria in microglia (A, B), in oligodendrocytes (C, D) in the SPPS and SPNS subgroups with shorter ( $<26$ years) and longer ( $>26$ years) duration of disease and $\mathrm{V} v$ and $\mathrm{N}$ of vacuoles in microglia in the subgroups with shorter $(<26$ years) and longer ( $>26$ years) duration of disease as compared to the control group (E, F). ${ }^{\star} p<0.05$; ${ }^{\star \star} p<0.01$. 

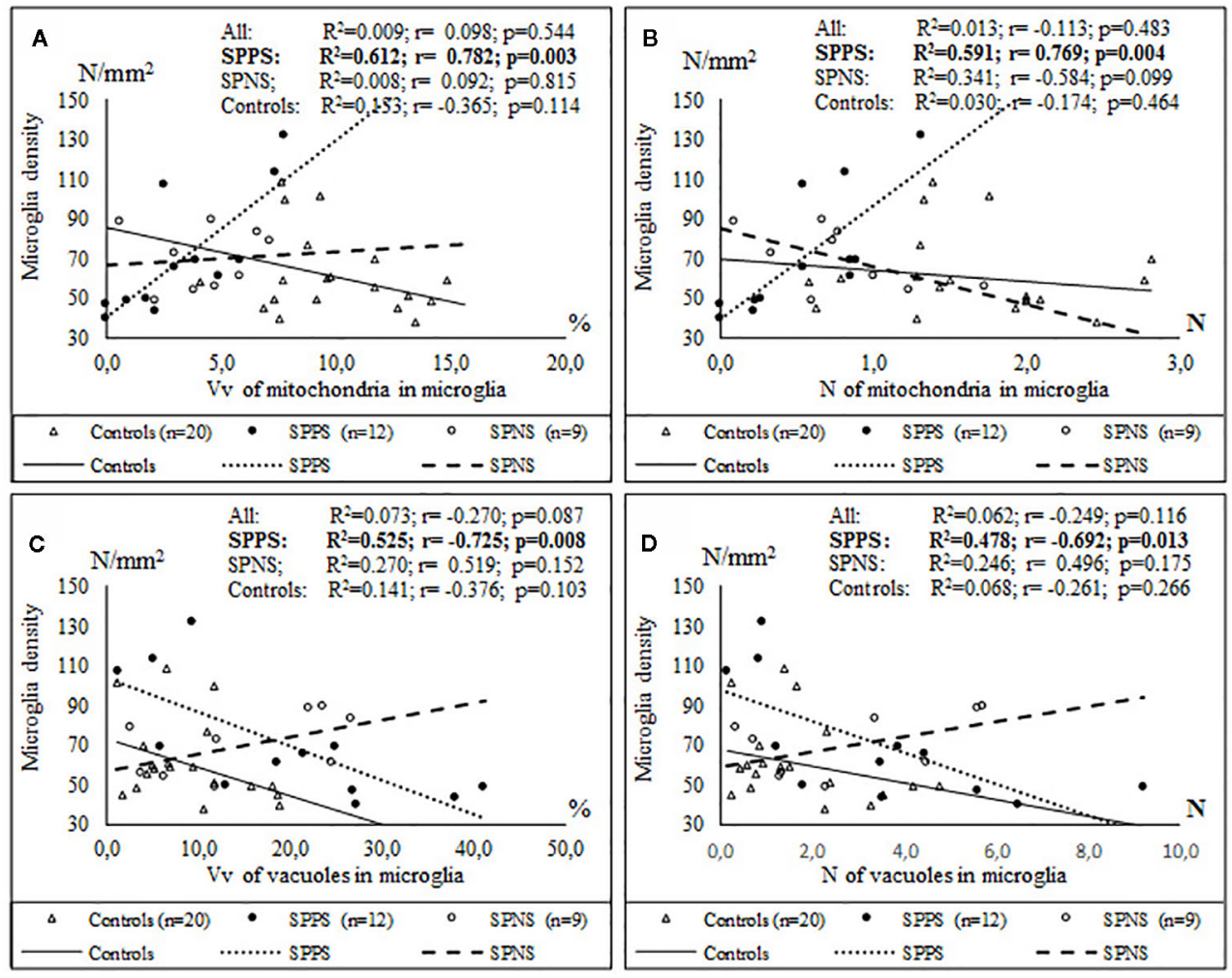

FIGURE 7 | Positive significant correlations between $\mathrm{V} v$ and $\mathrm{N}$ of mitochondria in microglia and microglial density (A, B) and negative significant correlations between $\mathrm{V} v$ and $\mathrm{N}$ of vacuoles in microglia and microglial density $(\mathbf{C}, \mathbf{D})$ in the SPPS subgroup.

We did not find the effects of neuroleptic medication on the parameters measured. Antipsychotics are known to inhibit microglial activation (69). Recently Du et al., (70) in the model of transient global cerebral ischemia showed an anti-depressant effect of minocycline by inhibiting microglia activation, promoting OPCs maturation and remyelination. Both typical and atypical neuroleptics decrease cytokines such as IL-2, IL-6 and TNFalpha by inhibiting microglial activation (71-73). Kung et al. (74) have reported a reduction in the numbers of mitochondrial profiles per axon terminal in the drug-free schizophrenia patients as compared to either on-drug patients or to controls. Taken together, the data suggest that the deficit of mitochondria in both microglia and oligodendrocytes is related to schizophrenia.

Recently we have reported reduced oligodendrocyte density $(-32 \%)$ in layer 5 of the PFC (Brodmann's area 10) in schizophrenia (12). In the present study we found dystrophic changes but no degeneration of oligodendrocytes in layer 5 of the PFC in schizophrenia. Thus, a prominent deficit of oligodendrocytes in layer 5 of the PFC cannot be explained by current oligodendrocyte degeneration, it may be the result of disrupted maturation and proliferation of oligodendrocyte progenitors in schizophrenia (75-78).

Oligodendrocytes and especially oligodendrocyte precursors are highly sensitive to inflammation, oxidative stress, hypoxiaischemia, elevated glutamate levels (8). Redox regulation has a crucial role in myelination and white matter maturation in the PFC (79). In response to stress, oligodendrocytes produce immune mediators that modulate activation of microglial cells (67). Oxidative stress during late adolescence impairs oligodendrocyte precursors signal transduction processes and disrupts oligodendrocyte maturation (80). ER stress and mitochondrial dysfunction are involved in death of oligodendrocyte precursors by unconjugated bilirubin (81). The disruption of glutamatergic, redox, immune systems could be deleterious for oligodendrocyte differentiation and myelination (82). $\mathrm{N}$-acetylcysteine, a precursor of endogenous antioxidant glutathione, diminish the cuprizone-induced behavioral changes and oligodendrocyte loss in male C57BL/7 mice due to its anti-inflammation actions (83). On the other hand, microglia contribute to maintenance of oligodendrocyte progenitors during adulthood and in adults (84). Microglia activation triggers apoptosis of oligodendrocyte precursors by HSP60 (85). Increased oxidative stress and oxidative DNA damage have been detected in nonremission patients with schizophrenia (86). Maas et al. (87) provides a hypothetic link between oxidative stress, hypomyelination of the PFC and cognitive symptoms in schizophrenia. Together these data provide evidence for the crucial role of oxidative stress in disturbed metabolism of oligodendrocytes and microglia in schizophrenia during brain development and in adult patients. 
We found that in the SPPS subgroup in both oligodendrocytes and microglia $\mathrm{Vv}$ and $\mathrm{N}$ of mitochondria were decreased in the subgroup with longer duration of disease ( $>26$ years) than in the subgroup with shorter duration of disease ( $<26$ years). These parameters were positively correlated between microglia and oligodendrocytes in the SPPS subgroup. Also $\mathrm{Vv}$ and $\mathrm{N}$ of vacuoles in microglia were significantly increased in the subgroup with longer duration of illness as compared to controls (Figure 6). Besides, area of nucleus of microglial cells was correlated negatively significantly with age in the SPPS subgroup. Neuroinflammation has recently been reported in the PFC in elderly chronic schizophrenia patients (88). Taken together, these data suggest that microglia is involved in a progressive course of schizophrenia. The suggestion is in line with the results of neuroimaging studies that "progressive" brain changes might occur in schizophrenia, supposedly associated with episodes of acute relapse $(89,90)$.

In our study $\mathrm{Vv}$ an $\mathrm{N}$ of mitochondria in microglia were correlated positively with microglial density, and $\mathrm{Vv}$ and $\mathrm{N}$ of vacuoles in microglia were correlated negatively with microglial density in the SPPS subgroup, though microglial density did not differ from the control group (Figure 7). Microglia are actively renewed in brain maintained by a balance of proliferation and apoptosis (91). This balance is probably disturbed in acute state of schizophrenia. Taken together the dystrophic alterations of microglia and adjacent oligodendrocytes in schizophrenia found in the present study may explain at least in part the association of a high relapse rate with poorer outcomes, reduced plasticity and functional disability in patients with schizophrenia.

\section{Limitations}

Our study has some limitations. We had to deal with a relatively small number of oligodendrocyte-microglial pairs. Many subjects in our study were older than 55 years old with long duration of disease (average 26 years). The effects of neuroleptic treatment were not determined. Two separate scales used at the time of autopsy were used for the estimation of predominantly positive and predominantly negative symptoms.

\section{CONCLUSION}

Dysregulated microglial reactivity and microglia dystrophy in acute stage of schizophrenia might contribute to the dystrophy of

\section{REFERENCES}

1. Friston K, Brown HR, Siemerkus J, Stephan KE. The dysconnection hypothesis. Schizophr Res (2016) 176(2-3):83-94. doi: 10.1016/j.schres.2016.07.014

2. Takahashi N, Sakurai T, Davis KL, Buxbaum JD. Linking oligodendrocyte and myelin dysfunction to neurocircuitry abnormalities in schizophrenia. ProgNeurobiol (2011) 93:13-24. doi: 10.1016/j.pneurobio.2010.09.004

3. Hoistad M, Segal D, Takahashi N, Sakurai T, Buxbaum JD, Hof PR. Linking white and grey matter in schizophrenia: oligodendrocyte and neuron pathology in the prefrontal cortex. Front Neuroanat (2009) 3:9. doi: 10.3389/neuro.05.009

4. Zhou Y, Fan L, Qiu C, Jiang T. Prefrontal cortex and the dysconnectivity hypothesis of schizophrenia. Neurosci Bull (2015) 31(2):207-19. doi: 10.1007/ s12264-014-1502-8 oligodendrocytes and might be involved in progressive course and reduced brain plasticity in chronic schizophrenia patients. Mitochondria in microglia and oligodendrocytes may be a target for treatment strategy of schizophrenia.

\section{DATA AVAILABILITY STATEMENT}

The datasets generated for this study are available on request to the corresponding author.

\section{ETHICS STATEMENT}

Consent for autopsy was obtained and approval for the study from the Ethics Committee of Mental Health Research Center was received.

\section{AUTHOR CONTRIBUTIONS}

NU designed the study, wrote, and revised the manuscript. OV performed morphometry and prepared the draft of the manuscript. VR performed statistical analysis. DO prepared and revised manuscript.

\section{FUNDING}

The study was supported from the Federal Budget by Mental Health Research Center, Russian Federation (the theme Nº5082014-0066).

\section{ACKNOWLEDGMENTS}

The authors thank Nadegda Matiatova for expert technical assistance. This study was supported from the Federal Budget.

5. Park JY, Park HJ, Kim DJ, Kim JJ. Positive symptoms and water diffusivity of the prefrontal and temporal cortices in schizophrenia patients: a pilot study. Psychiatry Res (2014) 224(1):49-57. doi: 10.1016/j.pscychresns.2014.07.003

6. Rotarska-Jagiela A, van de Ven V, Oertel-Knochel V, Uhlhaas PJ, Vogeley K, Linden DE. Resting-state functional network correlates of psychotic symptoms in schizophrenia. Schizophr Res (2010) 117(1):21-30. doi: 10.1016/ j.schres.2010.01.001

7. Garver D, Holcomb J, Christensen J. Compromised myelin integrity during psychosis with repair during remission in drug responding schizophrenia. Int J Neuropsychopharmacol (2008) 11:49-61. doi: 10.1017/S1461145707007730

8. Chew LJ, Fusar-Poli P, Schmitz T. Oligodendroglial alterations and the role of microglia in white matter injury: relevance to schizophrenia. Dev Neurosci (2013) 35:102-29. doi: 10.1159/000346157 
9. Hof PR, Haroutunian V, Friedrich VLJr, Byne W, Buitron C, Perl DP, et al. Loss and altered spatial distribution of oligodendrocytes in the superior frontal gyrus in schizophrenia. Biol Psychiatry (2003) 53(12):1075-85. doi: 10.1016/s0006-3223(03)00237-3

10. Uranova NA, Vostrikov VM, Orlovskaya DD, Rachmanova VI. Oligodendroglial density in the prefrontal cortex in schizophrenia and mood disorders:a study from the Stanley Neuropathology Consortium. Schizophr Res (2004) 67(2-3):269-75. doi: 10.1016/S0920-9964(03)00181-6

11. Vostrikov VM, Uranova NA, Orlovskaya DD. Deficit of perineuronal oligodendrocytes in the prefrontal cortex in schizophrenia and mood disorders. Schizophr Res (2007) 94(1-3):273-80. doi: 10.1016/ j.schres.2007.04.014

12. Kolomeets NS, Uranova NA. Reduced oligodendrocyte density in layer 5 of the prefrontal cortex in schizophrenia. Eur Arch Psychiatry Clin Neurosci (2019) 269(4):379-86. doi: 10.1007/s00406-018-0888-0

13. Uranova N, Orlovskaya D, Vikhreva O, Zimina I, Kolomeets N, Vostrikov V, et al. Electron microscopy of oligodendroglia in severe mental illness. Brain Res Bull (2001) 55(5):597-610. doi: 10.1016/s0361-9230(01)00528-7

14. Uranova NA, Vikhreva OV, Rachmanova VI, Orlovskaya DD. Ultrastructural alterations of myelinated fibers and oligodendrocytes in the prefrontal cortex in schizophrenia: a postmortem morphometric study. Schizophr Res Treat (2011) 2011:325789. doi: 10.1155/2011/325789

15. Vikhreva OV, Rakhmanova VI, Orlovskaya DD, Uranova NA. Ultrastructural alterations of oligodendrocytes in prefrontal white matter in schizophrenia: a post-mortem morphometric study. Schizophr Res (2016) 177:28-36. doi: 10.1016/j.schres.2016.04.023

16. Lake EMR, Steffler EA, Rowley CD, Sehmbi M, Minuzzi L, Frey BN, et al. Altered intracortical myelin staining in the dorsolateral prefrontal cortex in severe mental illness. Eur Arch Psychiatry Clin Neurosci (2017) 267(5):369-76. doi: 10.1007/s00406-016-0730-5

17. Mauney SA, Pietersen CY, Sonntag KC, Woo TU. Differentiation of oligodendrocyte precursors is impaired in the prefrontal cortex in schizophrenia. Schizophr Res (2015) 169(1-3):374-80. doi: 10.1016/ j.schres.2015.10.042

18. Hakak Y, Walker JR, Li C, Wong WH, Davis KL, Haroutunian V, et al. Genome-wide expression analysis reveals dysregulation of myelinationrelated genes in chronic schizophrenia. PNAS (2001) 98:4746-51. doi: 10.1073/pnas. 081071198

19. Katsel P, Davis KL, Li C, Tan W, Greenstein E, Kleiner Hoffman LB, et al. Abnormal indices of cell cycle activity in schizophrenia and their potential association with oligodendrocytes. Neuropsychopharmacol (2008) 33:29933009. doi: $10.1038 /$ npp.2008.19

20. Mitkus SN, Hyde TM, Vakkalanka R, Kolachana B, Weinberger DR, Kleinman JE, et al. Expression of oligodendrocyte-associated genes in dorsolateral prefrontal cortex of patients with schizophrenia. Schizophr Res (2008) 98(1-3):129-38. doi: 10.1016/j.schres.2007.09.032

21. Uranova NA, Vikhreva OV, Rakhmanova VI, Orlovskaya DD. Ultrastructural pathology of oligodendrocytes adjacent to microglia in prefrontal white matter in schizophrenia. NPJ Schizophr (2018) 4(1):26. doi: 10.1038/s41537018-0068-2

22. Monji A, Kato T, Kanba S. Cytokines and schizophrenia: Microglia hypothesis of schizophrenia. Psychiatry Clin Neurosci (2009) 63(3):257-65. doi: 10.1111/ j.1440-1819.2009.01945.x

23. Barron H, Hafizi S, Andreazza AC, Mizrahi R. Neuroinflammation and Oxidative Stress in Psychosis and Psychosis Risk. Int J Mol Sci (2017) 18(3): E651. doi: 10.3390/ijms18030651

24. Arion D, Unger T, Lewis DA, Levitt P, Mirnics K. Molecular evidence for increased expression of genes related to immune and chaperone function in the prefrontal cortex in schizophrenia. Biol Psychiatry (2007) 62:711-21. doi: 10.1016/j.biopsych.2006.12.021

25. Pasternak O, Kubicki M, Shenton ME. In vivo imaging of neuroinflammation in schizophrenia. Schizophr Res (2016) 173(3):200-12. doi: 10.1016/ j.schres.2015.05.034

26. Trepanier MO, Hopperton KE, Mizrahi R, Mechawar N, Bazinet RP. Postmortem evidence of cerebral inflammation in schizophrenia: a systematic review. Mol Psychiatry (2016) 21(8):1009-26. doi: 10.1038/ mp. 2016.90
27. van Kesteren CF, Gremmels H, de Witte LD, Hol EM, Van Gool AR, Falkai PG, et al. Immune involvement in the pathogenesis of schizophrenia: a metaanalysis on postmortem brain studies. Transl Psychiatry (2017) 7(3):e1075. doi: $10.1038 /$ tp.2017.4

28. Bayer TA, Buslei R, Havas L, Falkai P. Evidence for activation of microglia in patients with psychiatric illnesses. Neurosci Lett (1999) 271:126-8. doi: 10.1016/s0304-3940(99)00545-5

29. Wierzba-Bobrowicz T, Lewandowska E, Lechowicz W, Stepien T, Pasennik E. Quantitative analysis of activated microglia, ramified and damage of processes in the frontal and temporal lobes of chronic schizophrenics. Folia Neuropathol (2005) 43(2):81-9.

30. Radewicz K, Garey LJ, Gentleman SM, Reynolds R. Increase in HLA-DR immuno-reactive microglia in frontal and temporal cortex of chronic schizophrenics. J Neuropathol Exp Neurol (2000) 59:137-50. doi: 10.1093/ jnen/59.2.137

31. Fillman SG, Cloonan N, Catts VS, Miller LC, Wong J, McCrossin T, et al. Increased inflammatory markers identified in the dorsolateral prefrontal cortex of individuals with schizophrenia. Mol Psychiatry (2013) 18(2):20614. doi: $10.1038 / \mathrm{mp} .2012 .110$

32. Steiner J, Mawrin C, Ziegeler A, Bielau H, Ullrich O, Bernstein HG, et al. Distribution of HLA-DR-positive microglia in schizophrenia reflects impaired cerebral lateralization. Acta Neuropathol (2006) 112(3):305-16. doi: 10.1007/ s00401-006-0090-8

33. Busse S, Busse M, Schiltz K, Bielau H, Gos T, Brisch R, et al. Different distribution patterns of lymphocytes and microglia in the hippocampus of patients with residual versus paranoid schizophrenia: further evidence for disease course- related immune alterations? Brain Behav Immun (2012) 26 (8):1273-9. doi: 10.1016/j.bbi.2012.08.005

34. Doorduin J, de Vries EF, Willemsen AT, de Groot JC, Dierckx RA, Klein HC. Neuroinflammation in schizophrenia-related psychosis: a PET study. J Nucl Med (2009) 50(11):1801-7. doi: 10.2967/jnumed.109.066647

35. Bloomfield PS, Selvaraj S, Veronese M, Rizzo G, Bertoldo A, Owen DR, et al. Microglial activity in people at ultra high risk of psychosis and in schizophrenia: an [(11)C]PBR28 PET brain imaging study. Am J Psychiatry (2016), 173(1):44-52. doi: 10.1176/appi.ajp.2015.14101358

36. Takano A, Arakawa R, Ito H, Tateno A, Takahashi H, Matsumoto R, et al. Peripheral benzodiazepine receptors in patients with chronic schizophrenia: a PET study with [11C]DAA1106. Int J Neuropsychopharmacol (2010) 13 (7):943-50. doi: 10.1017/S146114571000031313,

37. De Picker L, Ottoy J, Verhaeghe J, Deleye S, Wyffels L, Fransen E, et al. Stateassociated cha ige' in longit.dina. $\left.{ }^{\mathrm{r}} 18 \mathrm{~F}\right]-\mathrm{PBR} 111$ TSPO PET imaging of psychosis patients: Evidence for the accelerated ageing hypothesis? Brain Behav Immun (2019) 77:46-54. doi: 10.1016/j.bbi.2018.11.318

38. van Berckel BN, Bossong MG, Boellaard R, Kloet R, Schuitemaker A, Caspers E, et al. Microglia activation in recent-age at schizophrenia: a quantitative (R)[11C]PK11195 positron emission tomography study. Biol Psychiatry (2008) 64(9):820-2. doi: 10.1016/j.biopsych.2008.04.025

39. Fillman SG, Weickert TW, Lenroot RK, Catts SV, Bruggemann JM, Catts VS, et al. Elevated peripheral cytokines characterize a subgroup of people with schizophrenia displaying poor verbal fluency and reduced broca's area volume. Mol Psychiatry (2016) 21:1090-8. doi: 10.1038/mp.2015.90

40. Xin L, Mekle R, Fournier M, Baumann PS, Ferrari C, Alameda L, et al. Genetic polymorphism associated prefrontal glutathione and its coupling with brain glutamate and peripheral redox status in early psychosis. Schizophr Bull (2016) 42(5):1185-96. doi: 10.1093/schbul/sbw038

41. Fraguas D, DIaz-Caneja CM, Pina-Camacho L, Janssen J, Arango C. Progressive brain changes in children and adolescents with early-onset psychosis: A meta-analysis of longitudinal MRI studies. Schizophr Res (2016) 173(3):132-9. doi: 10.1016/j.schres.2014.12.022

42. Namgaladze D, Khodzhaeva V, Brune B. ER- Mitochondria Communication in Cells of the Innate Immune System. Cells (2019) 8(9):1088. doi: 10.3390/ cells 8091088

43. Fan Y, Simmen T. Mechanistic Connections between Endoplasmic Reticulum (ER) Redox Control and Mitochondrial Metabolism. Cells (2019) 8(9):1071. doi: $10.3390 /$ cells 8091071

44. Roberts RC. Postmortem studies on mitochondria in schizophrenia. Schizophr Res (2017) 187:17-25. doi: 10.1016/j.43.2017.01.056 
45. Konradi C, Ongur D. Role of mitochondria and energy metabolism in schizophrenia and psychotic disorders. Schizophr Res (2017) 187:1-2. doi: 10.1016/j.schres.2017.07.007

46. Nascimento JM, Martins-de-Souza D. The proteome of schizophrenia. NPJ Schizophr (2015) 1:14003. doi: 10.1038/npjschz.2014.3

47. Kim Y, Vadodaria KC, Lenkei Z, Kato T, Gage FH, Marchetto MC, et al. Mitochondria, Metabolism, and Redox Mechanisms in Psychiatric Disorders. Antioxid Redox Signal (2019) 31(4):275-317. doi: 10.1089/ars.2018.7606

48. Maurer I, Zierz S, Moller H. Evidence for a mitochondrial oxidative phosphorylation defect in brains from patients with schizophrenia. Schizophr Res (2001) 48(1):125-36. doi: 10.1016/s0920-9964(00)00075-x

49. Iwamoto K, Bundo M, Kato T. Altered expression of mitochondria-related genes in postmortem brains of patients with bipolar disorder or schizophrenia, as revealed by large-scale DNA microarray analysis. Hum Mol Genet (2005) 14(2):241-53. doi: 10.1093/hmg/ddi022

50. Flatow J, Buckley P, Miller BJ. Meta-analysis of oxidative stress in schizophrenia. Biol Psychiatry (2013) 74(6):400-9. doi: 10.1016/j.biopsych.2013.03.018

51. Rajasekaran A, Venkatasubramanian G, Berk M, Debnath M. Mitochondrial dysfunction in schizophrenia:pathways, mechanisms and implications. Neurosci Biobehav Rev (2015) 48:10-21. doi: 10.1016/j.neubiorev.2014.11.005

52. Picard M, McEwen BS. Psychological Stress and Mitochondria: A Systematic Review. Psychosom Med (2018) 80(2):141-53. doi: 10.1097/PSY.0000000000000545

53. Do KQ, Trabesinger AH, Kirsten-Kruger M, Lauer CJ, Dydak U, Hell D, et al. Schizophrenia: glutathione deficit in cerebrospinal fluid and prefrontal cortex in vivo. Eur J Neurosci (2000) 12(10):3721-28. doi: 10.1046/j.14609568.2000.00229.x

54. Gawryluk JW, Wang J- F, Andreazza AC, Shao L, Young LT. Decreased levels of glutathione, the major brain antioxidant, in post-mortem prefrontal cortex from patients with psychiatric disorders. Int J Neuropsychopharmacol (2011) 14:123-30. doi: 10.1017/S1461145710000805

55. Nakanishi H, Wu Z. Microglia-aging: roles of microglial lysosome- and mitochondria-derived reactive oxygen species in brain aging. Behav Brain Res (2009) 201(1):1-7. doi: 10.1016/j.bbr.2009.02.001

56. Saetre P, Emilsson L, Axelsson E, Kreuger J, Lindholm E, Jazin E. Inflammation-related genes up-regulated in schizophrenia brains. $B M C$ Psychiatry (2007) 7:46. doi: 10.1186/1471-244X-7-46

57. Arion D, Unger T, Lewis DA, Levitt P, Mirnics K. Molecular evidence for increased expression of genes related to immune and chaperone function in the prefrontal cortex in schizophrenia. Biol Psychiatry (2007) 62(7):711-21. doi: 10.1016/j.biopsych.2006.12.021

58. Mizoguchi Y, Kato TA, Horikawa H, Monji A. Microglial intracellular Ca(2+) signaling as a target of antipsychotic actions for the treatment of schizophrenia. Front Cell Neurosci (2014) 8:370. doi: 10.3389/fncel.2014.00370

59. He B. Viruses, endoplasmic reticulum stress, and interferon responses. Cell Death Differ (2006) 13(3):393-403. doi: 10.1038/sj.cdd.4401833

60. Ogata M, Hino S, Saito A, Morikawa K, Kondo S, Kanemoto S, et al. Autophagy is activated for cell survival after endoplasmic reticulum stress. Mol Cell Biol (2006) 26(24):9220-31. doi: 10.1128/MCB.01453-06

61. Lemasters JJ. Selective mitochondrial autophagy, or mitophagy, as a targeted defense against oxidative stress, mitochondrial dysfunction, and aging. Rejuvenation Res (2005) 8(1):3-5. doi: 10.1089/rej.2005.8.3

62. Bernstein HG, Keilhoff G, Dobrowolny H, Steiner J. Enhanced mitochondrial autophagy (mitophagy) in oligodendrocytes might play a role in white matter pathology in schizophrenia. Med Hypotheses (2019) 134:109443. doi: 10.1016/ j.mehy.2019.109443

63. Streit WJ, Xue QS, Tischer J, Bechmann I. Microglial pathology. Acta Neuropathol Commun (2014) 2:142. doi: 10.1186/s40478-014-0142-6

64. Bisht K, Sharma KP, Lecours C, Sanchez MG, El Hajj H, Milior G, et al. Dark microglia: A new phenotype predominantly associated with pathological states. Glia (2016) 64(5):826-39. doi: 10.1002/glia.22966

65. So JS. Roles of Endoplasmic Reticulum Stress in Immune Responses. Mol Cells (2018) 41(8):705-16. doi: 10.14348/molcells.2018.0241

66. Bronner DN, Abuaita BH, Chen X, Fitzgerald KA, Nunez G, He Y. Endoplasmic reticulum stress activates the inflammasome via NLRP3- and caspase-2-driven mitochondrial damage. Immunity (2015) 43(3):451-62. doi: 10.1016/j.immuni.2015.08.008
67. Peferoen L, Kipp M, van der Valk P, van Noort JM, Amor S. Oligodendrocytemicroglia cross-talk in the central nervous system. Immunology (2014) 141 (3):302-313. doi: 10.1111/imm.12163

68. Wierzba-Bobrowicz T, Lewandowska E, Kosno-Kruszewska E, Lechowicz W, Pasennik E, Schmidt-Sidor B. Degeneration of microglial cells in frontal and temporal lobes of chronic schizophrenics. Folia Neuropathol (2004) 42 (3):157-65.

69. Kato TA, Monji A, Mizoguchi Y, Hashioka S, Horikawa H, Seki Y, et al. AntiInflammatory properties of antipsychotics via microglia modulations: are antipsychotics a 'fire extinguisher' in the brain of schizophrenia? Mini Rev Med Chem (2011) 11(7):565-74. doi: 10.2174/138955711795906941

70. Du B, Li H, Zheng H, Fan C, Liang M, Lian Y, et al. Minocycline Ameliorates Depressive-Like Behavior and Demyelination Induced by Transient Global Cerebral Ischemia by Inhibiting Microglial Activation. Front Pharmacol (2019) 10:1247. doi: 10.3389/fphar.2019.01247

71. Kato TA, Yamauchi Y, Horikawa H, Monji A, Mizoguchi Y, Seki Y, et al. Neurotransmitters, psychotropic drugs and microglia: clinical implications for psychiatry. Curr Med Chem (2013) 20:331-44. doi: 10.2174/0929867311320030003

72. Seki Y, Kato TA, Monji A, Mizoguchi Y, Horikawa H, Sato-Kasai M, et al. Pretreatment of aripiprazole and minocycline, but not haloperidol, suppresses oligodendrocyte damage from interferon-y-stimulated microglia in co-culture model. Schizophr Res (2013) 151(1 -3):20-8. doi: 10.1016/j.schres.2013.09.011

73. Shao Y, Peng H, Huang Q, Kong J, Xu H. Quetiapine mitigates the neuroinflammation and oligodendrocyte loss in the brain of C57BL/6 mouse following cuprizone exposure for one week. Eur J Pharmacol (2015) 765:249-57. doi: 10.1016/j.ejphar.2015.08.046

74. Kung L, Roberts RC. Mitochondrial pathology in human schizophrenic striatum: a postmortem ultrastructural study. Synapse (1999) 31:67-75. doi: 10.1002/(SICI)1098-2396(199901)31:1<67::AID-SYN9>3.0.CO;2-\#

75. Mauney SA, Pietersen CY, Sonntag KC, Woo TU. Differentiation of oligodendrocyte precursors is impaired in the prefrontal cortex in schizophrenia. Schizophr Res (2015) 169(1-3):374-80. doi: 10.1016/j.schres.2015.10.042

76. McPhie DL, Nehme R, Ravichandran C, Babb SM, Ghosh SD, Staskus A, et al. Oligodendrocyte differentiation of induced pluripotent stem cells derived from subjects with schizophrenias implicate abnormalities in development. Transl Psychiatry (2018) 8(1):230. doi: 10.1038/s41398-018-0284-6

77. Raabe FJ, Slapakova L, Rossner MJ, Ludovico Cantuti-Castelvetri L, Simons M, Falkai PG, et al. Oligodendrocytes as a New Therapeutic Target in Schizophrenia: From Histopathological Findings to Neuron-Oligodendrocyte Interaction. Cells (2019) 8(12):1496. doi: 10.3390/cells8121496

78. Schmitt A, Simons M, Cantuti-Castelvetri L, Falkai P. A new role for oligodendrocytes and myelination in schizophrenia and affective disorders? Eur Arch Psychiatry Clin Neurosci (2019) 269(4):371-72. doi: 10.1007/s00406-019-01019-8

79. Monin A, Baumann PS, Griffa A, Xin L, Mekle R, Fournier M, et al. Glutathione deficit impairs myelin maturation: relevance for white matter integrity in schizophrenia patients. Mol Psychiatry (2015) 20(7):827-38. doi: $10.1038 / \mathrm{mp} .2014 .88$

80. French HM, Reid M, Mamontov P, Simmons RA, Grinspan JB. Oxidative stress disrupts oligodendrocyte maturation. J Neurosci Res (2009) 87 (14):3076-87. doi: 10.1002/jnr.22139

81. Barateiro A, Vaz AR, Silva SL, Fernandes A, Brites D. ER stress, mitochondrial dysfunction and calpain/JNK activation are involved in oligodendrocyte precursor cell death by unconjugated bilirubin. Neuromol Med (2012) 14 (4):285-302. doi: 10.1007/s12017-012-8187-9

82. Steullet P, Cabungcal JH, Monin A, Dwir D, O'Donnell P, Cuenod M, et al. Redox dysregulation, neuroinflammation, and NMDA receptor hypofunction: A "central hub" in schizophrenia pathophysiology? Schizophr Res (2016) 176 (1):41-51. doi: 10.1016/j.schres.2014.06.021

83. Zhang L, Xu S, Huang Q, Xu H. N- acetylcysteine attenuates the cuprizoneinduced behavioral changes and oligodendrocyte loss in male C57BL/7 mice via its anti-inflammation actions. J Neurosci Res (2018) 96(5):803-16. doi: $10.1002 /$ jnr. 2418980

84. Hagemeyer N, Hanft KM, Akriditou MA, Unger N, Eun S, Park E, et al. Microglia contribute to normal myelinogenesis and to oligodendrocyte progenitor maintenance during adulthood. Acta Neuropathol (2017) 134 (3):441-58. doi: 10.1007/s00401-017-1747-1 
85. Li Y, Zhang R, Hou X, Zhang Y, Ding F, Li F, et al. Microglia activation triggers oligodendrocyte precursor cells apoptosis via HSP60. Mol Med Rep (2017) 16(1):603-8. doi: 10.3892/mmr.2017.6673

86. Sertan Copoglu U, Virit O, Hanifi Kokacya M, Orkmez M, Bulbul F, Binnur Erbagci A, et al. Increased oxidative stress and oxidative DNA damage in nonremission schizophrenia patients. Psychiatry Res (2015) 229(1-2):200-5. doi: 10.1016/j.psychres.2015.07.036

87. Maas DA, Valles A, Martens GJM. Oxidative stress, prefrontal cortex hypomyelination and cognitive symptoms in schizophrenia. Transl Psychiatry (2017) 7(7):e1171. doi: 10.1038/tp.2017.138

88. Lopez-Gonzalez I, Pinacho R, Vila E, Escanilla A, Ferrer I, Ramos B. Neuroinflammation in the dorsolateral prefrontal cortex in elderly chronic schizophrenia. Eur Neuropsychopharmacol (2019) 29(3):384-96. doi: 10.1016/ j.euroneuro.2018.12.011

89. Andreasen NC, Nopoulos P, Magnotta V, Pierson R, Ziebell S, Ho BC. Progressive brain change in schizophrenia: a prospective longitudinal study of first-episode schizophrenia. Biol Psychiatry (2011) 70:672-9. doi: 10.1016/ j.biopsych.2011.05.017
90. van Haren NEM, Kahn RS. Progressive brain tissue loss in schizophrenia. Schizophr Res (2016) 173(3):121-3. doi: 10.1016/j.schres.2016.03.023

91. Askew K, Li K, Olmos-Alonso A, Garcia-Moreno F, Liang Y, Richardson P, et al. Coupled Proliferation and Apoptosis Maintain the Rapid Turnover of Microglia in the Adult Brain. Cell Rep (2017) 18(2):391-405. doi: 10.1016/ j.celrep.2016.12.041

Conflict of Interest: The authors declare that the research was conducted in the absence of any commercial or financial relationships that could be construed as a potential conflict of interest.

Copyright $\odot 2020$ Uranova, Vikhreva, Rakhmanova and Orlovskaya. This is an openaccess article distributed under the terms of the Creative Commons Attribution License (CC BY). The use, distribution or reproduction in other forums is permitted, provided the original author(s) and the copyright owner(s) are credited and that the original publication in this journal is cited, in accordance with accepted academic practice. No use, distribution or reproduction is permitted which does not comply with these terms. 